\title{
Efektivitas Suplemen Zink pada Pneumonia Anak
}

\author{
Audrey M. I. Wahani
}

Bagian Ilmu Kesehatan Anak, Fakultas Kedokteran Universitas Sam Ratulangi/RSU. Prof. Dr. R.D. Kandou, Manado

Latar belakang. Pneumonia merupakan penyebab utama morbiditas dan mortalitas anak berusia di bawah lima tahun. Diperkirakan $20 \%$ dari seluruh kematian pada anak di bawah lima tahun disebabkan oleh infeksi saluran napas bawah akut dengan $90 \%$ di antaranya disebabkan oleh pneumonia. Zink adalah mikronutrien penting pada manusia dan terbukti penting untuk daya tahan tubuh, disamping itu anakanak terutama di negara berkembang kekurangan zink. Defisiensi zink mengakibatkan dampak serius bagi kesehatan terutama sistem imun melemah sebagai akibatnya terjadi peningkatan prevalensi penyakit infeksi pada anak seperti pneumonia. Pemberian zink telah diteliti sebagai suatu untuk pengobatan dan pencegahan dari pneumonia.

Tujuan. Mengetahui pengaruh pemberian suplemen zink dalam perbaikan respon klinik anak dengan pneumonia serta waktu pemulihan dan lama tinggal pasien di rumah sakit.

Metode. Penelitian quasi eksperimental dengan metode post-test design with unequivalent control group dalam bentuk observasi prospektif dilakukan pada anak usia 2 bulan-5 tahun yang menderita pneumonia di ruang rawat inap Rumah Sakit Umum Pusat Prof.Dr.R.D.Kandou Manado.

Hasil. Didapatkan pemberian zink bermanfaat memperbaiki waktu demam 22,5\%, sesak napas $28,9 \%$ dan laju napas $65,8 \%$ lebih singkat dibandingkan kontrol. Tidak terdapat perbedaan yang bermakna $(\mathrm{p}>0,05)$ pada kesembuhan batuk dan waktu rawat inap pada kelompok zink maupun kontrol.

Kesimpulan. Pemberian suplemen zink $20 \mathrm{mg}$ pada anak dengan pneumonia efektif dalam pemulihan demam, sesak napas, dan laju pernapasan. Sari Pediatri 2012;13(5):357-61.

Kata kunci: suplemen zink, pneumonia anak

$\mathrm{P}$ neumonia tercatat sebagai masalah kesehatan utama pada anak di negara berkembang yang merupakan penyebab utama morbiditas dan mortalitas anak berusia di bawah lima tahun

\section{Alamat korespondensi:}

Dr. Audrey Wahani, Sp.A. Bagian Ilmu Kesehatan Anak Fakultas Kedokteran UNSRAT/RSUP Prof. Dr. R. D. Kandou, Manado. Tel. (0431) 821652, Fax. (0431) 859091, E-mail: audrey_wahani@yahoo.co.id (balita). Diperkirakan 20\% dari seluruh kematian pada anak di bawah lima tahun disebabkan oleh infeksi saluran pernafasan akut (pneumonia, bronkiolitis dan bronkitis) dengan $90 \%$ di antaranya disebabkan oleh pneumonia. ${ }^{1}$

Kejadian pneumonia di Indonesia pada balita diperkirakan 10\%-20\% per tahun dengan angka kematian 6 per 1000. Pemerintah telah merencanakan untuk menurunkan insiden pneumonia menjadi 3 per 
1000 balita pada tahun 2010. Namun, keberhasilan tersebut bergantung pada banyak faktor risiko, salah satunya adalah malnutrisi. ${ }^{2}$

Kekurangan zink dihubungkan dengan penurunan imunitas dan peningkatan penyakit infeksi serius. Kekurangan zink kemungkinan menjadi penyebab utama peningkatan mortalitas bayi yang kekurangan nutrisi di negara berkembang. ${ }^{3}$ Zink plasma yang rendah berkaitan dengan peningkatan kejadian risiko infeksi saluran napas bawah akut. ${ }^{4}$ Konsumsi zink yang kurang akan mengganggu keseluruhan fungsi imun dan ketahanan terhadap infeksi karena penekanan fungsi timus, perkembangan limfosit $T$, limfoproliferasi, dan fungsi sel B tergantung sel T. ${ }^{5}$ Penelitian oleh Bhutta dkk, ${ }^{6}$ menunjukkan bahwa suplemen zink pada anak-anak di negara berkembang berhubungan dengan laju penurunan yang nyata pada diare dan pneumonia. Hal tersebut juga ditegaskan oleh Brooks $\mathrm{dkk}^{7}$ dalam penelitiannya mendapatkan secara klinik dan statistik, zink dan antimikroba standar mempercepat pemulihan pneumonia berat pada anak usia di bawah dua tahun. Penelitian yang dilakukan oleh Aggrawal dkk ${ }^{8}$ mengindikasikan bahwa suplemen zink pada anak menunjukkan penurunan frekuensi dan keparahan penyakit saluran pernapasan. Zink telah terbukti mencegah pneumonia dan efektif mengobati pneumonia berat.'

Data surveilans terpadu penyakit berbasis rumah sakit rawat inap tahun 2008 di RSUP Prof.Dr.R.D.Kandou Manado memperlihatkan pneumonia merupakan penyakit terbanyak, diikuti oleh penyakit diare dan gastroenteritis pada anak berusia 1 bulan- 5 tahun. Penggunaan suplemen zink di RSUP Prof.Dr.R.D.Kandou masih sangat terbatas dalam pengobatan pneumonia pada anak.

Berdasarkan hal tersebut, maka dilakukan suatu penelitian untuk memperoleh gambaran mengenai manfaat penggunaan zink pada anak yang dirawat inap dengan pneumonia di RSUP Prof.Dr.R.D.Kandou, Manado periode Oktober 2009-Februari 2010.

\section{Metode}

Penelitian quasi eksperimental dengan metode post-test design with unequivalent control group dilakukan dalam bentuk observasi prospektif. Pengamatan dilakukan terhadap pasien yang mendapat terapi standar dengan penambahan suplemen zink dan pasien yang mendapat terapi standar tanpa penambahan suplemen zink. Hasil dianalisis terhadap luaran klinik yaitu demam, laju pernafasan, sesak nafas, batuk, dan lama rawat inap.

Penelitian dilakukan pada pasien usia 2 bulan 5 tahun dengan diagnosis pneumonia dan dirawat di ruang rawat inap RSUP Prof. Dr. R. D. Kandou Manado terhitung sejak Oktober 2009-Februari 2010. Pasien dengan gizi buruk, komplikasi lain dan penolakan untuk berpartisipasi tidak diikutsertakan dalam penelitian.

Data dikelompokkan menjadi data kuantitatif dan disajikan dalam bentuk tabel dan tekstual. Data diuji dengan metode statistik melalui program SPSS 16.0, dengan menggunakan uji chi square, uji-t dan uji Mann-Whitney dengan tingkat kepercayaan 95\% dan dianggap bermakna bila $\mathrm{p}<0,05$.

\section{Hasil}

Selama penelitian terdapat 61 anak pasien pneumonia yang masuk dalam penelitian ini, yang dibagi dalam 2 kelompok yaitu 28 anak mendapat suplemen zink dan 33 anak tidak mendapat suplemen zink sebagai kelompok kontrol.

Pada Tabel 1 terlihat kelompok usia yang paling banyak menderita pneumonia adalah kelompok usia 2 bulan - 1 tahun (33/61 pasien), jenis kelamin adalah laki-laki (38/61 pasien), status gizi adalah baik (47/61 pasien), dan yang diberikan ASI (49/61 pasien). Pada data tersebut karakteristik subyek penelitian tidak berbeda secara bermakna berdasarkan usia, jenis kelamin, status gizi, dan ASI ( $\mathrm{p}>0,05)$.

Tabel 2 menunjukkan lama demam pada pasien pneumonia yang diberikan suplemen zink lebih singkat dibandingkan dengan kelompok kontrol, yaitu $(2,21 \pm 0,50)$ hari versus $(2,85 \pm 0,68)$ hari, bermakna secara statistik $(\rho<0,05)$. Pada perbandingan waktu sesak nafas pada pasien pneumonia yang diberikan suplemen zink lebih singkat dibandingkan dengan kelompok kontrol, yaitu $(1,57 \pm 0,57)$ hari versus $(2,21 \pm 0,70)$ hari, bermakna secara statistik $(\rho<0,05)$.

Waktu yang diperlukan untuk perbaikan laju nafas pada pasien pneumonia yang diberikan suplemen zink lebih singkat dibandingkan dengan kelompok kontrol, yaitu $(8,46 \pm 5,17)$ jam versus $(24,73 \pm 15,06)$ jam $(\rho<0,05)$. Sedangkan lama rawat inap pada pasien pneumonia yang diberikan 
Audrey M. I. Wahani: Efektivitas suplemen zink pada pasien pneumonia

Tabel 1. Karakteristik subyek penelitian

\begin{tabular}{|c|c|c|c|c|}
\hline \multirow{2}{*}{$\begin{array}{l}\text { Karakteristik } \\
\quad(\mathrm{n}=61)\end{array}$} & \multicolumn{2}{|c|}{ Perlakuan } & \multirow{2}{*}{$\mathrm{X} 2$} & \multirow{2}{*}{$\rho$} \\
\hline & Zink n (\%) & Kontrol n (\%) & & \\
\hline \multicolumn{5}{|l|}{ Usia } \\
\hline 2 bln -1 thn & $13(46,4)$ & $20(60,6)$ & 1,226 & 0,268 \\
\hline$>1$ thn -5 thn & $15(53,6)$ & $13(39,4)$ & & \\
\hline \multicolumn{5}{|l|}{ Jenis kelamin } \\
\hline Laki - laki & $16(57,1)$ & $22(66,7)$ & 0,585 & 0,444 \\
\hline Perempuan & $12(42,9)$ & $11(33,3)$ & & \\
\hline \multicolumn{5}{|l|}{ Status gizi } \\
\hline Baik & $21(75,0)$ & $26(78,8)$ & 0,123 & 0,726 \\
\hline Kurang & $7(25,0)$ & $7(21,2)$ & & \\
\hline \multicolumn{5}{|l|}{ ASI } \\
\hline Ya & $21(75,0)$ & $28(84,8)$ & 0,930 & 0,335 \\
\hline Tidak & $7(25,0)$ & $5(15,2)$ & & \\
\hline
\end{tabular}

Signifikan $\mathrm{p}<0,05$

Tabel 2. Lama demam dan sesak nafas pada kelompok zink dan kelompok kontrol.

\begin{tabular}{|c|c|c|c|c|c|}
\hline \multirow[t]{2}{*}{ Perlakuan } & \multicolumn{2}{|c|}{ Zink } & \multicolumn{2}{|c|}{ Kontrol } & \multirow{2}{*}{$\begin{array}{c}\rho \\
\text { (Mann-Whitney) }\end{array}$} \\
\hline & Rerata $\pm S B$ & Median & Rerata $\pm S B$ & Median & \\
\hline Lama demam (hari) & $2,21 \pm 0,50$ & 2 & $2,85 \pm 0,68$ & 3 & $<0,001^{*}$ \\
\hline Waktu sesak nafas (hari) & $1,57 \pm 0,57$ & 2 & $2,21 \pm 0,70$ & 2 & $<0,001^{*}$ \\
\hline
\end{tabular}

*signifikan $\rho<0,05$

Tabel 3. Waktu perbaikan laju nafas dan lama rawat inap pada kelompok zink dan kelompok kontrol.

\begin{tabular}{lcccc}
\hline Perlakuan & Zink & Kontrol & T & $\rho$ \\
& Rerata \pm SB & Rerata \pm SB & & \\
\hline Laju nafas membaik (jam) & $(8,46 \pm 5,17)$ & $(24,73 \pm 15,06)$ & $-5,444$ & $<0,001^{*}$ \\
Lama rawat (hari) & $(6,64 \pm 2,78)$ & $(7,12 \pm 3,00)$ & $-0,642$ & 0,523 \\
\hline
\end{tabular}

*signifikan $\mathrm{p}<0,05$

Tabel 4. Kesembuhan batuk pada kelompok zink dan kelompok kontrol

\begin{tabular}{lccc}
\hline Perlakuan & $\begin{array}{c}\text { Sembuh } \\
\mathrm{n}(\%)\end{array}$ & $\begin{array}{c}\text { Tidak sembuh } \\
\mathrm{n}(\%)\end{array}$ & $\rho$ \\
\hline Zink & $11(57,9)$ & $17(40,5)$ & 0,206 \\
Kontrol & $8(42,1)$ & $25(59,5)$ & \\
\hline
\end{tabular}

*signifikan $\rho<0,05$

suplemen zink lebih singkat dibandingkan dengan kelompok kontrol, yaitu $(6,64 \pm 2,78)$ hari VS $(7,12 \pm 3,00)$ hari, namun secara statistik tidak bermakna $(\rho>0,05)$ (Tabel 3).
Terlihat tidak ada perbedaan bermakna secara statistik (Tabel 4) kesembuhan batuk pada kedua kelompok perlakuan $(\rho>0,05)$. Kesembuhan batuk pada kelompok zink 11 anak $(57,9 \%)$ dan tidak sembuh 17 (40,5\%), sedangkan kesembuhan batuk pada kelompok kontrol 8 anak $(42,1 \%)$ dan tidak sembuh 25 anak $(59,5 \%)$.

\section{Pembahasan}

Menurut Roth dkk, ${ }^{10}$ pada Bulletin of the World Health Organization defisiensi zink pada bayi dan anak akan mempengaruhi fungsi leukosit, ekspresi sitokin dan 
membran mukosa. Prevalensi defisiensi zink yang tinggi di negara berkembang akan menyebabkan penurunan imunitas dan peningkatan penyakit infeksi serius. ${ }^{11}$ Menurut Aggarwal $\mathrm{dkk}^{8}$ menegaskan bahwa suplementasi zink oral harian dan mingguan secara rutin selama tiga bulan secara signifikan mengurangi kejadian infeksi saluran nafas bawah akut.

Untuk meneliti danpak perlakuan suplemen zink terhadap luaran perjalanan pneumonia anak, pada penelitian kami ditentukan tingkat kesembuhan pneumonia dengan menghitung waktu demam, sesak nafas, perbaikan laju nafas kembali normal, batuk selama perawatan di rumah sakit, dan lama rawat inap. Menurut Brooks $\mathrm{dkk}^{7}$ pengobatan dengan 20 mg zink perhari mempercepat pemulihan pneumonia berat pada anak. Pemberian suplemen zink akan menurunkan 45\% kejadian infeksi saluran nafas bawah akut pada anak. ${ }^{12}$ Dijelaskan oleh Bhutta $\mathrm{dkk}^{6}$ bahwa kejadian pneumonia pada anak di negara berkembang berkurang dengan pemberian suplemen zink sebesar $41 \%$. Demam, sianosis, batuk, takipnea, retraksi merupakan prediktor paling kuat adanya pneumonia. World Health Organization mengembangkan pedoman diagnosis dan tata laksana sederhana untuk negara berkembang berdasarkan gejala klinis yang dapat langsung dideteksi. Gejala klinis yang sederhana meliputi nafas cepat, sesak nafas, dan berbagai tanda bahaya agar anak segera dirujuk ke pelayanan kesehatan. ${ }^{13}$

Pada penelitian Mahalanabis $\mathrm{dkk},{ }^{14}$ pengobatan zink pada anak laki-laki lebih cepat menurunkan durasi demam dan mengurangi sakit. Pada penelitian Purwaningsih $^{15}$ didapatkan durasi demam pada anak yang mendapatkan zink pada dua bulan pertama akan menurunkan rerata demam 2,58 hari. Penelitian Brooks $\mathrm{dkk}^{7}$ mendapatkan pemakaian suplemen zink secara teratur akan menurunkan durasi kesembuhan anak dengan pneumonia berat. Pneumonia anak yang menerima standar terapi antibiotik ditambah dengan suplemen zink akan memperpendek durasi chest indrawing dan hipoksia. Shankar dan Prasad ${ }^{16}$ menyatakan bahwa zink berperan dalam status imunitas. Menurut Bose $\mathrm{dkk}^{17}$ tidak ada perbedaan dampak batuk yang signifikan dengan kelompok plasebo, sedangkan Sazawal $\mathrm{dkk}^{12}$ menyatakan peningkatan batuk dijumpai pada kelompok zink, meskipun mengalami penurunan infeksi saluran nafas bawah akut, mungkin merupakan indikasi mekanisme pertahanan pasien yang membaik dan perbaikan sistem imun pada anak. ${ }^{18}$
Temuan kami menunjukkan adanya manfaat pemberian suplemen zink $20 \mathrm{mg}$ perhari, pada peningkatan pemulihan tanda dan gejala pneumonia yaitu demam, laju nafas, dan sesak nafas.

\section{Daftar pustaka}

1. WHO. Acute respiratory infection in children. Diunduh dari: http://who.int. 2009. Diakses tanggal 23 Mei 2009.

2. Anonim. Guideline for the management of community acquired pneumonia in childhood. British Thoracic Society Standart of Care Comitte-Thorax. 2002; 57. Diunduh dari http://brit-thoracic.org/guideline. Diakses tanggal 27 Juli 2009.

3. Haider BA, Humayun Q, Bhutta Z.A. Zinc supplementation as an adjunct to antibiotics in the treatment of pneumonia in children 2 to 59 months of age (protocol). The Cochrane Collaboration, 2009.

4. Bahl R, Bhandri N, Hambidge KM, Bhan MK. Plasma zinc A predictor of diarrheal and respiratory morbidity in children in an urban slum setting. Am J Clin Nutr 1998; 68: 414-7.

5. Shankar AH, Prasad AS. Zinc and immune function: The biological basis of altered resistency to infection. Am J Clin Nut 1998; 68: 447-63.

6. Bhutta ZA, Black RE, Brown KH, Gardner JM, Gore S, Hidayat A. Prevention of diarrhea and pneumonia by zinc supplementation in children in developing countries: pooled analysis of randomized controlled trials: Zinc Investigators' Collaborative Group. J Pediatr 1999; 135: 689-97.

7. Brooks WA, Yunus M, Santosham M, Wahed MA, Nahar $\mathrm{K}$, Yeasmin S. Zinc for severe pneumonia in very young children: double blind placebo controlled trial. Lancet 2004; 363: 1683-8.

8. Aggarwal R, Sentz J, Miller MA. Role of zinc administration in prevention of childhood diarrhea and respiratory illness: a metaanalysis. Pediatrics 2007; 119: 1120-30.

9. Caulfield LE, Richard SA, Rivera JA, Musgrove P, Black RE. Stunting, wasting, and micronutrients deficiency disorders. Dalam: Jamison DT, Breman JG, Meashman A, penyunting. Disease control priorities in developing countries. Edisi ke-2. Oxford University Press; 2006 . h.551-67.

10. Roth DE, Caulfiled LE, Ezzati M, Black RE. Acute lower respiratory infection in childhood : opportunities for reducing the global through nutritional interventions,. Bull World Health Org 2008; 86: 356-64. 
11. Krebs NF, Hambidge KM, Primank LE. Normal childhood nutrition \& its disorder. Dalam: Hay WW, penyunting. Current pediatrics diagnosis \& treatment. Edisi ke-16. New York: Lange Medical Books/ Mc Graw Hill;1999.h.285.

12. Sazawal S, Black RE, Jalla S, Mazumdar S, Sinha A, Bhan MK. Zinc supplementation reduced the incidence of acute lower respiratory infections in infants and preschool children: A double blind controlled trial. Pediatrics 1998: 1021-5.

13. WHO. Pneumonia: The forgotten killer of children. UNICEF/WHO, 2006.

14. Mahalanabis D, Lahiri M, Paul D, Gupta A, Wahed MA, Khaled MA. Randomized double blind placebo controlled clinical trial of the efficacy of treatment with zinc or vitamin $A$ in infants and young children with severe acute lower respiratory infection. Am J Clin Nutr 2004; 79: 430-6.
15. Purwaningsih E. A Community based randomized controlled trial of iron and zinc supplementation in Indonesian infants: Effects on child morbidities. Media Medika Indonesiana 2005; 40:52-6.

16. Shankar AH, Prasad AS. Zinc and immune function: the biological basis of altered resistance to infection. Am J Clin Nutr 1998;68:447-63.

17. Bose A, Coles CL, Gunavathi, John H, Moses P, Raghupathy P. Efficacy of zinc for severe pneumonia in hospitalized children <2 years old. Am J Clin Nutr 2006;83:1089-96.

18. Ruel MT, Rivera JA, Santizo MT, Lonerdal B, Brown $\mathrm{KH}$. Impact of zinc supplementation on morbidity from diarrhea and respiratory infections among rural Guatemalan children. Pediatrics 1997;99:808-13. 